\title{
TUMOR PARDO TIBIAL COMO FORMA DE PRESENTACIÓN DE UN HIPERPARATIROIDISMO PRIMARIO
}

\section{TIBIAL BROWN TUMOR AS A PRESENTATION OF PRIMARY HYPERPARATHYROIDISM TUMOR MARROM TIBIAL COMO FORMA DE APRESENTAÇÃO DE HIPERPARATIREOIDISMO PRIMÁRIO}

Darío Álvaro Rueda ${ }^{1,2}$, Bárbara Nazionale ${ }^{1}$, Ana Jiménez Espinal', Paola Finocchietto ${ }^{1}$, Diego Carroza ${ }^{1}$, Horacio di Fonzo $^{1}$.

El tumor pardo es una lesión ósea que surge por el exceso de la actividad de los osteoclastos en el contexto de un hiperparatiroidosmo muy evolucionado. Si bien no es una neoplasia, puede mimetizarla en su manifestación radiológica, la imagen lítica.

\section{Conceptos clave:}

Importancia: desde que el dosaje de PTH y vitamina $D$ son realizados de forma rutinaria, el compromiso óseo por su exceso y déficit respectivamente, han pasado a constituir una rareza en medicina. La osteítis fibrosa quística es una complicación ósea causada por un hiperparatiroidismo muy evolucionado de baja prevalencia en países desarrollados. Su diagnóstico puede ser desafiante, ya que clínica e imagenológicamente puede confundirse con otras enfermedades, como el tumor óseo de células gigantes o metástasis óseas. Para su diagnóstico etiológico es necesario la determinación de PTH en sangre y la gammagrafía paratiroidea con 99mTcsestamibi. El tratamiento va dirigido a corregir las alteraciones del calcio, suprimir el exceso de PTH mediante paratiroidectomia y osteosíntesis en el caso de fracturas patológicas.

1- Primera Catedra de Medicina Interna del Hospital de Clínicas José de San Martin. Universidad de Buenos Aires; Argentina.

2- E-mail de contacto: darioalvarorueda@gmail.com

\section{Resumen:}

La osteítis fibrosa quística es la complicación de un hiperparatiroidismo muy evolucionado. Debido a que la determinación del calcio, hormona paratiroides y vitamina $\mathrm{D}$ han pasado a ser estudios rutinarios, esta complicación ósea es infrecuente en los países occidentales. Sin embargo, debe ser considerada en el diagnóstico diferencial de hipercalcemia y lesiones óseas líticas. El tratamiento de esta entidad va dirigido a suprimir el exceso de hormona paratiroides mediante la paratiroidectomia y osteosíntesis en los casos de fracturas patológicas. Se presenta el caso de una paciente con hiperparatiroidismo primario y un tumor pardo en la tibia derecha.

Palabras clave: hiperparatiroidismo primario; osteítis fibrosa quística/complicaciones; diagnóstico diferencial.

\section{Abstract:}

Cystic fibrous osteitis is a complication of a very evolved hyperparathyroidism. Because the determination of calcium, parathyroid hormone and vitamin $D$ have become routine studies, this bone complication is uncommon in western countries. However, it should be considered in the differential diagnosis of hypercalcemia and lytic bone lesions. The treatment is to suppress the excess parathyroid hormone by parathyroidectomy and osteosynthesis in pathological fracture. We present the case of a female patient with primary hyperparathyroidism and a brown tumor in the right tibia.

Keywords: hyperparathyroidism primary; osteitis fibrosa cystica/complications; diagnosis differential.

\section{Resumo}

A osteite fibrosa cística é uma complicação de um hiperparatireoidismo altamente evoluído. Como a determinação de cálcio, hormônio paratireóide e vitamina D se tornaram estudos de rotina, essa complicação óssea é incomum nos países ocidentais. No entanto, deve ser considerado no diagnóstico diferencial de hipercalcemia e lesões ósseas líticas. O tratamento dessa entidade visa suprimir o excesso de hormônio da paratireóide por paratireoidectomia e osteossíntese nos casos de fraturas patológicas. É apresentado o caso de um paciente com hiperparatireoidismo primário e um tumor marrom na tibia direita.

Palavras-chave: hyperparathyroidism primary; osteitis fibrosa cystica/complications; diagnosis differential. 
A principios del siglo $X X$, cuando se describió el hiperparatiroidismo primario (HPTP), los pacientes presentaban las complicaciones clásicas de la enfermedad, donde el sistema esquelético era el más afectado ${ }^{1}$. Este compromiso óseo, llamado osteítis fibrosa quística (OFQ), se caracteriza por resorción ósea subperióstica, osteólisis ósea en algunos huesos (cráneo en aspecto de sal y pimienta), quistes óseos y el tumor pardo. Desde que la determinación de la calcemia y vitamina $D$ es realizada de forma rutinaria, estas manifestaciones óseas son infrecuentes en los países occidentales. Sin embargo, aún se pueden ver casos de hiperparatiroidismo con su forma clásica de compromiso óseo ${ }^{1,2}$.

Mujer de 45 años de edad, sin antecedentes patológicos, había comenzado 10 meses previos con una tumoración dolorosa en la región pretibial derecha, asociado a astenia y nauseas esporádicamente. Al descubrirse en un centellograma óseo una lesión con captación del radiofármaco en la diáfisis tibial derecha la paciente fue derivada a oncología (imagen $1 \mathrm{~A}$ ). Ante el empeoramiento de los síntomas y el hallazgo de hipercalcemia la paciente ingresó en nuestra institución. En el laboratorio de ingreso tenía una $\mathrm{Hb} 14 \mathrm{gr} / \mathrm{dl}$, leucocitos $12080 \mathrm{~mm} 3$, plaquetas $240000 \mathrm{~mm} 3$, creatinina $0,89 \mathrm{mg} / \mathrm{dl}$, calcio iónico $1,7 \mathrm{mmol} / \mathrm{l}$, fosfato $2,2 \mathrm{mg} / \mathrm{dl}$, fosfatasa alcalina $787 \mathrm{Ul} / \mathrm{L}$, vitamina D3 5 $\mathrm{ng} / \mathrm{ml}$, PTH $>2500 \mathrm{pg} / \mathrm{ml}$. En las imágenes de la tibia derecha se evidenció una lesión lítica (imagen 2 y 3). Posterior al tratamiento de la hipercalcemia con hidratación con solución fisiológica, pamidronato y calcitonina, la paciente presentó mejoría del dolor y disminución de tamaño del tumor pretibial. Fue realizado un centellograma de paratiroides con Mibi-Tc 99m que informó alta probabilidad de adenoma/hiperplasia de glándula paratiroide inferior derecha (imagen 1B). Posterior a la paratiroidectomía la PTH fue de $50 \mathrm{pg} / \mathrm{ml}$; la paciente requirió aporte endovenoso de calcio en el posoperatorio por haber desarrollado síndrome de hueso hambriento. El informe anatomopatológico fue compatible con un adenoma paratiroideo.

Que un paciente se presente con una lesión ósea lítica e hipercalcemia orientan en primer lugar a una enfermedad oncológica, puesto que en la actualidad las manifestaciones óseas del HPTP son infrecuentes, y no es tenido en cuenta en el diagnóstico diferencial ${ }^{2}$.

El tumor pardo es una lesión ósea benigna uni o multifocal, que representa la etapa terminal de la enfermedad ósea dependiente del hiperparatiroidismo ${ }^{2}$. El exceso de hormona paratiroidea conduce a una mayor actividad osteoclástica, activación de la cascada inflamatoria, que resulta en infiltración de macrófagos y depósito de tejido fibrovascular a nivel óseo ${ }^{3}$.

Los tumores pardos afectan con mayor frecuencia la mandíbula, el cráneo, la clavícula, las costillas, hueso femoral y la columna vertebral ${ }^{2}$. Estas lesiones óseas pueden ser indistinguible, tanto por imágenes como por histología del tumor de células gigante, granuloma de células gigante y el quiste óseo aneurismático. Por lo tanto es importante la valoración bioquímica del calcio, PTH y vitamina $D$ para diferenciar estas entidades ${ }^{2}$.

Nuestra paciente, había tardado varios meses antes de consultar, y además del hiperparatiroidismo primario tenia déficit de vitamina $D$, lo cual pudo agravar el compromiso óseo ${ }^{2,3}$.

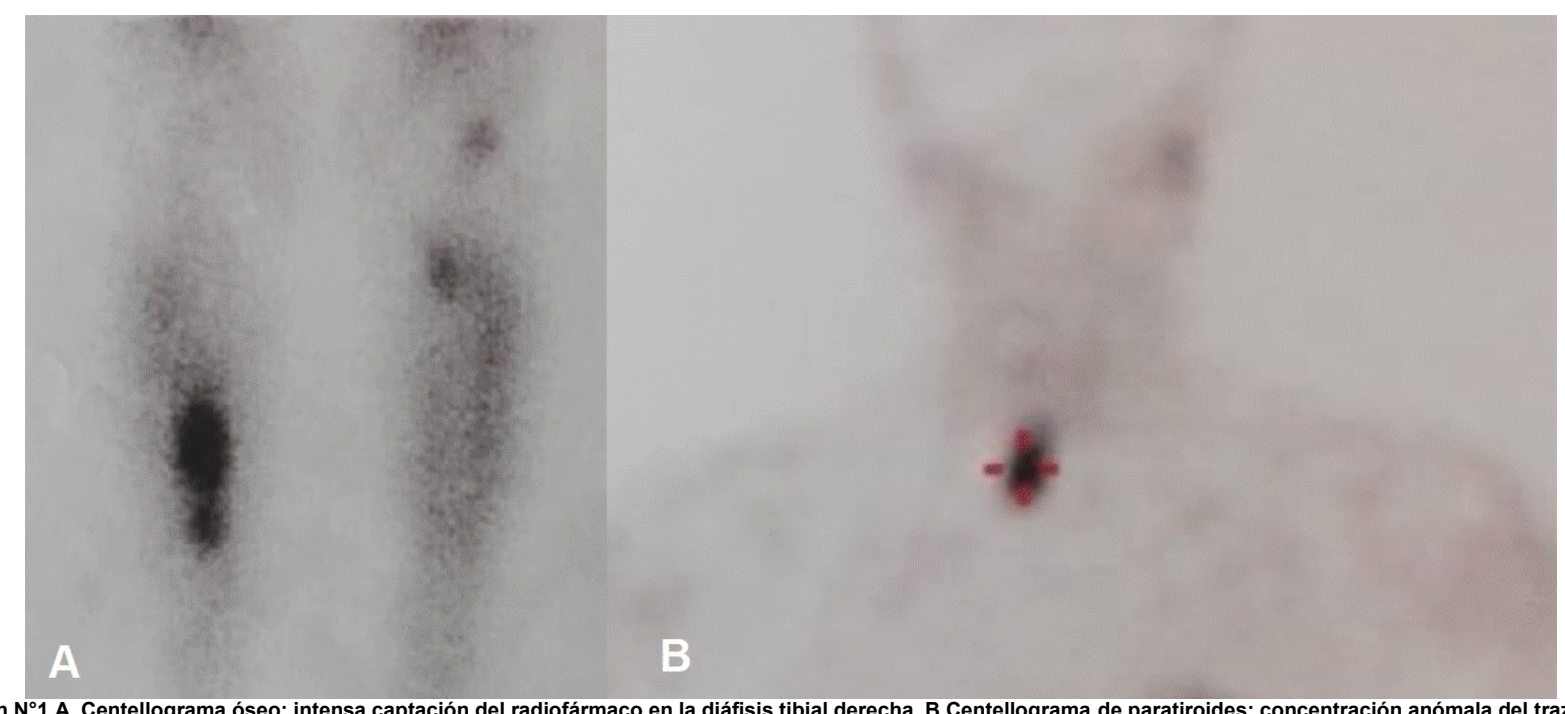




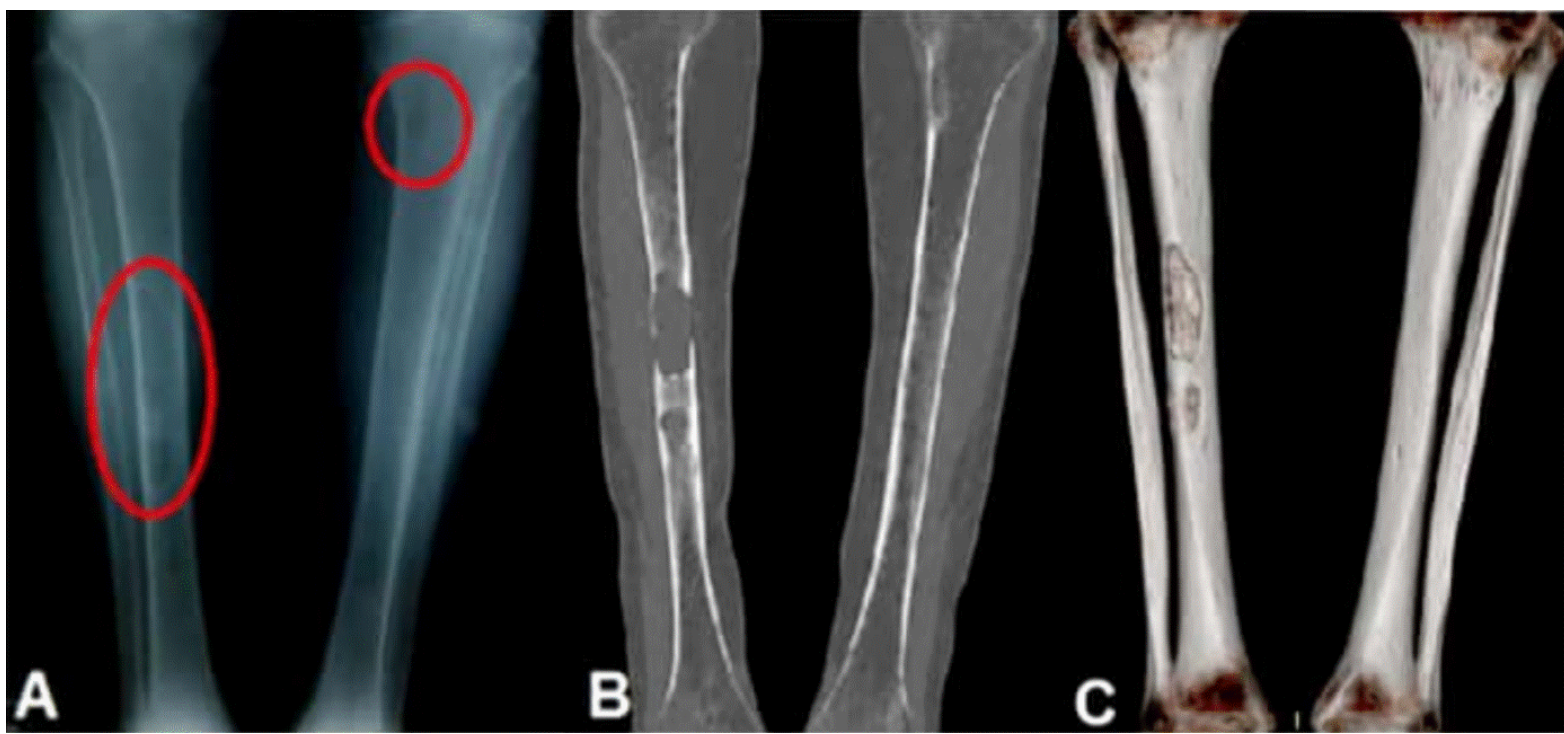

Imagen $N^{\circ}$ 2. A. Radiografía de miembros inferiores: imagen lítica en la diáfisis tibial derecha y en la tibia proximal izquierda. B Tomografía: imagen lítica irregular de densidad de partes blandas que mide $41 \times 20 \mathrm{~mm}$ en la diáfisis tibial derecha, debajo de esta y en la unión diáfisis metafisaria tibial izquierda otras imágenes más pequeñas de similares características. C Reconstrucción tomográfica de ambas tibias

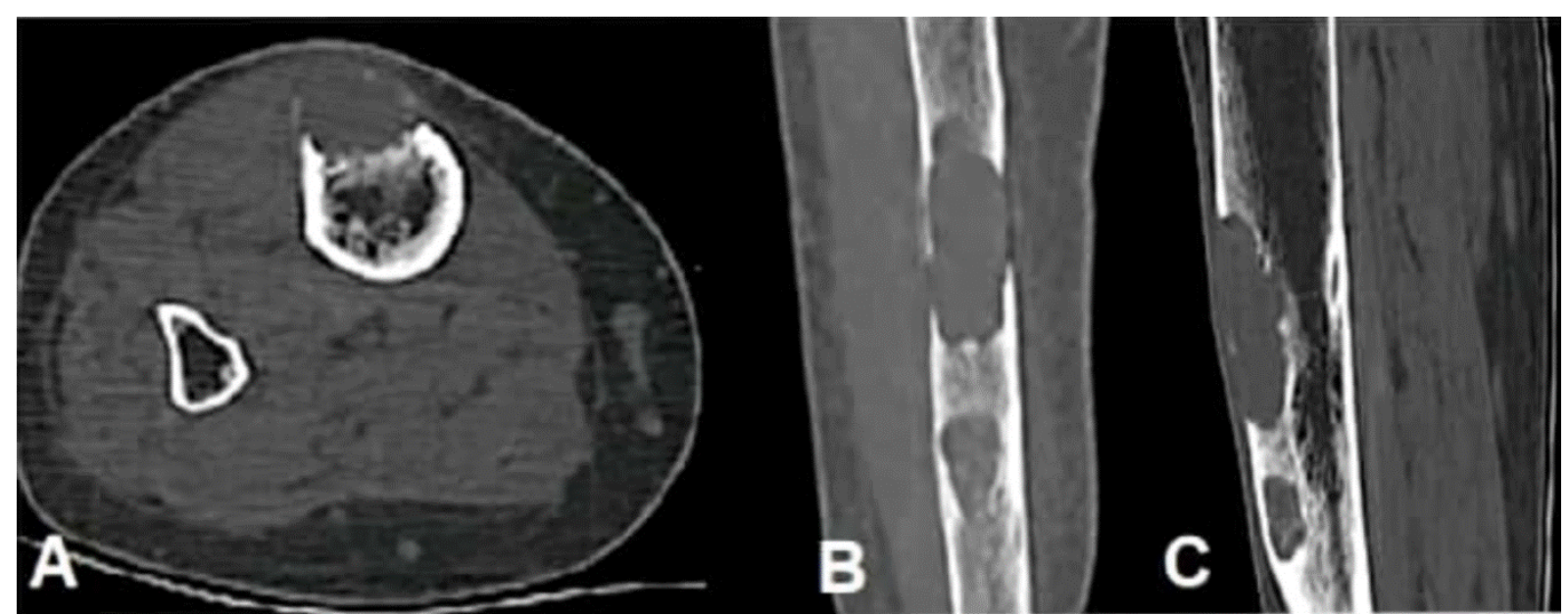

Imagen $\mathbf{N}^{\circ}$ 3. Tomografía de diáfisis tibial en el plano axial, coronal y sagital. Imagen lítica de densidad de partes blandas con pérdida de la cortical.

\section{Limitaciones de responsabilidad:}

Los autores realizaron el manuscrito de forma independiente, sin ayuda de la institución en la que trabajan u otro organismo.

Fuentes de apoyo:

Ninguna

\section{Originalidad:}

Los autores del manuscrito Tumor pardo tibial como forma de presentación de un hiperparatiroidismo primario, enviado para la categoría imagen en medicina, declaran que es un trabajo inédito. El mismo no ha sido presentado en ningún congreso de medicina, ni enviado a otra revista para su publicación o revisión.

\section{Cesión de derechos:}

Se ceden los derechos de autor a la Universidad Nacional de Córdoba para la publicar en la Revista de la Facultad de Ciencias Médicas de Córdoba y realizar la traducción en inglés.

\section{Conflicto de interés:}

Los autores del manuscrito declaran no tener conflictos de intereses con otros autores, instituciones, laboratorios $\mathrm{u}$ otros.

\section{Bibliografía}

1. Minisola S, Gianotti L, Bhadada S, Silverberg SJ. Classical complications of primary hyperparathyroidism. Best Pract Res Clin Endocrinol Metab. 2018 Dec;32(6):791-803. doi: 10.1016/j.beem.2018.09.001.

2. Misiorowski W, Czajka-Oraniec I, Kochman M, Zgliczyński W, Bilezikian JP. Osteitis fibrosa cystica-a forgotten radiological feature of primary hyperparathyroidism. Endocrine. 2017 Nov;58(2):380-385. doi: 10.1007/s12020-017-1414-2.

3. Jervis $L$, James $M$, Howe $W$, Richards S. Osteolytic lesions: osteitis fibrosa cystica in the setting of severe primary hyperparathyroidism. BMJ Case Rep. 2017 May 28;2017:bcr2017220603. doi: 10.1136/bcr-2017-220603. 